\title{
Down syndrome: An overview
}

Author:
Samuel Otabor Wajuihian ${ }^{1}$
Affiliation:
'Discipline of Optometry,
University of KwaZulu-Natal,
South Africa
Corresponding author:
Samuel Otabor Wajuihian,
swajuihian @mweb.co.za
Dates:
Received: 08 Jan. 2016
Accepted: 01 Apr. 2016
Published: 06 July 2016
smart phone or
mowile device
to cite this article:
Wajuihian SO. Down
syndrome: An overview.
Afr Vision Eye Health.
2016;75(1), a346. http://
dx.doi.org/10.4102/aveh.
v75i1.346
Copyright:
Oc 2016. The Author(s).
Licensee: AOSIS. This work
is licensed under the
Creative Commons
Attribution License.

Optometrists as primary eye care providers examine patients from diverse populations, including those with special needs such as Down syndrome. Down syndrome is a chromosomal abnormality associated with several health conditions including vision anomalies such as refractive, accommodative and vergence anomalies, as well as ocular pathology. In this article, a narrative review of Down syndrome including the background, historical perspective, aetiology and genetic mechanisms, types, epidemiology, as well as the physical and medical profile of Down syndrome is presented.

\section{Introduction}

Optometrists as primary eye care providers examine patients from diverse populations including those with special needs (PSNs). These patients include those with Down syndrome (DS), traumatic brain injury, autistic spectrum disorder, cerebral palsy, fragile $\mathrm{X}$ syndrome, learning disorders and psychological or psychiatric disorders..$^{1,2}$ In general, normal vision is important for the intellectual and overall development of an individual. Vision anomalies such as refractive, binocular anomalies, as well as ocular diseases are prevalent in DS populations. ${ }^{3,4}$ Therefore, if not identified and treated, vision impairment would constitute an additional burden to the persons with DS. As a primary eye care profession, optometry plays an important role in diagnosing and treating vision anomalies in PSNs. Even though the optometry curriculum covers topics on PSNs including DS, information on these populations is limited in the optometric literature. Sand et al. ${ }^{1}$ noted that, generally, the exposure and training of optometrists towards PSNs are inadequate. This concern is important as the average optometrist is likely to be consulted by PSNs in the course of their clinical duties. It is therefore the responsibility of the optometrist to obtain essential information and acquire the necessary skills to diagnose and treat vision anomalies in patients of diverse needs.

The aim of this article is to present a narrative overview of DS. The information contained will provide optometrists with basic information needed to communicate and relate with the patient with DS. The review comprises an introduction and overview of DS, historical perspective and terminologies, aetiology and genetic mechanism, types, epidemiology, physical and medical profile of DS, as well as screening and diagnosis. The scope of this article is firmly on providing the basic information and does not review oculo-visual anomalies in DS. Various strategies were applied to search relevant information on DS. The electronic databases searched included PubMed, Medline, Science Direct, Google Scholar, EBSCO and Embase using the terms Down's syndrome, Down syndrome and trisomy 21. Relevant articles published in English on reference lists were identified and retrieved from electronic and print journals.

\section{An overview of Down syndrome}

DS is a genetic disorder, which is due to the presence of 47 chromosomes instead of 46, with an extra copy of chromosome 21.5,6,7 The extra copy of chromosome 21, which may either be full or partial, depending on the variant, causes the abnormality and associated structural and functional anomalies of the bodily systems. ${ }^{5,6}$ It is consistent in the literature that advanced maternal age (AMA) is a primary risk factor in DS births. $5,6,7,8,9,10,11,12,13,14,15$ A major cause of foetal death in humans, about $50 \%$ of spontaneous foetal loss during pregnancy (before 15 weeks of gestation), are related to DS. ${ }^{9}$ DS is the most commonly diagnosed chromosomal abnormality in live-born infants and the most recognised congenital aneuploidy (presence of an erroneous number of chromosomes, e.g. 45 or 47) associated with delayed physical and mental development. DS is the most frequent genetic cause of intellectual disability (ID),${ }^{10,15}$ which is a main clinical feature of DS. Thus, most persons with DS have some degree of ID that affects learning and cognition. ${ }^{10,15}$ Most students with DS receive special education, while some can benefit from inclusive classroom settings. ${ }^{10}$ 
The effects of DS differ among individuals depending on the extent of abnormality ${ }^{11,15}$; therefore, mental abilities, physical development, personality, capabilities and talents vary considerably. ${ }^{11,12}$ The nature of the abnormality and the physical characteristics make the individuals with DS resemble one another rather than their own family members. ${ }^{2,415}$ However, only less than $5 \%$ is hereditary. ${ }^{14,15}$

DS has considerable health cost implications, given the individual and socio-economic consequences. ${ }^{9}$ DS is found in all races, nationalities, religions or socio-economic levels. ${ }^{13,14}$ The life expectancy and quality of life for affected people have increased remarkably due to improved medical care, general awareness, as well as increased social interactions. ${ }^{10,15}$ The estimated life expectancy of persons with DS has increased from just 12 years in the 1940s to an average of 55-60 years in the present decade, particularly in developed countries. ${ }^{10}$

\section{Historical review and terminologies applied to Down syndrome}

The historical developments of DS have been remarkable over the years. An earlier description of DS was reported by Jean Etienne Dominique Esquirol in 1838 and Edouard Seguin in 1844 and 1846..$^{13,16,17}$ However, it was John Langdon Down, a British physician who gave a comprehensive description of DS in his landmark presentation titled: 'Observations on an Ethnic Classification of Idiots' in 1866. ${ }^{18}$ According to Down, 'I have been able to find among the large number of idiots and imbeciles which come under my observation... very large number of congenital idiots are typical Mongols'. Down continued:

The Mongolian type of idiocracy.... are always congenital idiots, and never result from accidents after uterine life. They are, for the most part, instances of degeneracy arising from tuberculosis in the parents ... (p. 2)

Down observed that 'the patients' resembled one another as if they were siblings; they possessed a broad, flat face, a thick tongue and a small nose, narrow palpebral fissures, obliquely placed eyes, roundish and laterally extended cheeks, long tongue and the degrees of their intellectual impairment varied. Down's descriptions of the patients were based on their physical and facial resemblance to people of the Mongolian descent and he called them 'Mongolian idiots'. Subsequently, Down's description generated a lot of controversy as people of the Mongolian race found his description derogatory. ${ }^{9,13,18}$ Another remarkable milestone in the history of DS is that, in 1909, Shuttlewort recognised AMA as an aetiological factor in DS birth. ${ }^{16}$

The maternal age-aetiology link gave a new direction towards genetic investigations. Thus, in 1932, a Dutch ophthalmologist named Waardenburg and an American geneticist named Davenport hypothesised that 'Mongolism' might be due to chromosomal abnormalities. ${ }^{13,19}$ The works by Waardenburg and Davenport paved way to several genetic studies, and with the invention of the karyotyping technique (analysis of the structure of chromosomes within an individual cell) in the 1950s, it became possible to study chromosomes and chromosomal abnormalities in detail. ${ }^{13}$ In 1956, Tjio and Levan (cited in Cullen and Buttler) ${ }^{20}$ established that human cells have only 46 chromosomes or 23 pairs, comprising one pair of sex chromosomes (the $\mathrm{X}$ and $\mathrm{Y}$ chromosomes) contrary to an earlier theory of 24 pairs of chromosomes. ${ }^{20}$ In 1959, a French geneticist Jerome Lejeune and colleagues as well as Patricia Jacobs and colleagues ${ }^{19,21}$ who were working independently in England showed that DS is caused by a trisomy (triplication) of chromosome 21 . Other types of DS, translocation and mosaicism (explained later in the review) were described in subsequent years.

Terminologies applied to describe DS are diverse. Various terms including Mongolism, Mongolian idiocy, Mongoloid, Mongolian Idiots, Mongolian Imbecile, Langdon Down anomaly, Down's syndrome anomaly, congenital acromicria or trisomy 21 anomaly have been used to describe DS. . $3,16,17,20,22$ In 1961, renowned biomedical scientists (including John Langdon Down) discouraged researchers from using the word 'Mongolism' and suggested the use of 'Langdon Down anomaly', 'Down's syndrome/anomaly', 'trisomy 21 anomaly' or 'congenital acromicria'. ${ }^{13,22,23}$ Furthermore, the Mongolian delegates in 1965 submitted an objection to the World Health Organization (WHO) suggesting that the use of the term 'Mongol' or 'Mongolism' be discontinued due to its derogatory and racial connotations. Subsequently, the WHO officially discontinued references to mongolisms in all of its publications. ${ }^{5,22,23}$ The possessive use of ' $s$ ' in Down was also addressed. In 1975, at the United States National Institutes of Health's conference on standardisation of the nomenclature of malformations recommended eliminating the possessive form stating that, 'The possessive use of an eponym should be discontinued, since the author (Langdon Down) neither had nor owned the disorder'. ${ }^{22}$ Although both the possessive and non-possessive forms are used in the literature, 'Down syndrome' (non-possessive form) is more commonly used in the USA, Canada and other countries, while 'Down's syndrome' (possessive form) is commonly used in some European countries including the United Kingdom..$^{22}$ In the current literature, DS is used interchangeably as trisomy 21 as this is the dominant variant of DS.

\section{Genetic mechanisms and aetiology of chromosomal anomalies in Down syndrome}

Genes are located in the chromosomes. Beside the egg and sperm cells which have 23 individual chromosomes, there are 46 chromosomes, made up of 23 homologous (identical pairs) in each human cell, thus an individual has 23 chromosomes from each parent. Human chromosomes comprise 22 pairs of autosomes (non-sex chromosomes) and a pair of sex chromosomes $(X X, X Y)$. These chromosomes are numbered according to their sizes from 1 to $22 \cdot{ }^{6,7,8,24,25}$ During the development of egg or less commonly, in the sperm cells, errors may occur at the migration stage (segregation step) 
of meiosis. With this error, there is non-disjunction (improper separation of chromosomes) of the chromosomes, ${ }^{6,8,24,25}$ which result in an egg or sperm cell with the probability that some may have only 22 chromosomes while others, 24 chromosomes. As the cells divide, the extra chromosome is replicated in every cell of the body. The presence of three copies of chromosome 21 in all cells of the body is called trisomy. ${ }^{6,8,24,25}$

There are three main steps in the first meiotic cell division in humans, namely, pairing, recombination and chromosomal segregation steps. ${ }^{8,26}$ In the first step, homologous pairs of chromosomes locate and pair off with their partners. The second step known as genetic recombination involves the exchange of genetic materials among the paired homologous pairs. ${ }^{26}$ In the third step referred to as the chromosomal segregation step, each of the chromosomal pairs separate from their partners at metaphase stage to yield two daughter cells. This segregation step now produces 23 pairs of chromosomes. ${ }^{26}$

If a gamete (sex cells-sperm or ova) with an abnormal number of chromosomes merges with a normal gamete, the resulting embryo will have an abnormal number of 47 chromosomes instead of $466^{6,8,24,25}$ The error in the distribution of the chromosomes occurs at the time of the production of the egg or sperm before fertilisation so that the extra chromosome 21 is present in all the cells of the baby that arise from the fertilised egg. They, therefore, have 47 chromosomes in each cell instead of the usual $466^{6,8,24,25}$ The extra genetic materials cause abnormal development of cells leading to characteristic intellectual, medical and physical abnormalities in persons with trisomy $21.6,8,24,25,26,27$

\section{Types of Down syndrome}

Three variants of DS, trisomy 21, translocation and mosaic, 5,6 are known. Regardless of the genetic variation or mode of transmission, people with DS have a portion of chromosome 21 in some or all of their cells. ${ }^{5,6}$ Trisomy 21 is the most common type of DS and the exact cause is unknown. The errors begin in either the sperm or the egg, with the presence of the extra chromosome before the egg and sperm unite..$^{5,6,27}$ Trisomy 21 compromises about 95\% of all cases ${ }^{6,24}$; hence, trisomy (triplication) 21 is used synonymously as DS, and the number 21 implies that it occurs at chromosome number 21. Non-disjunction causing trisomy 21 is of maternal origin in about $88 \%$ of cases and occurs more frequently in older cells, which accounts for older women giving birth to offspring with trisomy $21.8,26,28$

Translocation occurs before fertilisation where a part of an extra copy of chromosome 21 breaks off during cell division and becomes translocated (attached) to another chromosome in the egg or sperm cell. Affected individuals have two normal copies of chromosome 21, in addition to an extra attached chromosome $21 ., 6,25$ If this happens with change of genetic material or joining of entire chromosome with another, then the individual is said to have a balanced translocation. ${ }^{6,25}$ In this case, the individual will be clinically normal although there is still a risk of producing chromosomally unbalanced translocation as the sperm or ova from individuals with balanced translocation have a high risk of producing an abnormal offspring. ${ }^{5,6,25}$ DS due to translocation is the only variant that occurs independent of maternal age and may be inherited from either parent. ${ }^{6,25}$ Approximately $4 \%$ of people with DS have translocation, ${ }^{5,6,25}$ which may either be reciprocal or Robertsonian. ${ }^{6}$ Reciprocal translocations are the most common type and involve an exchange of chromosome between any of the different types, for example, between chromosome 1 and chromosome 9. Robertsonian translocations only involve exchanges among chromosome numbers 13, 14, 15,21 and $22.6,25$

The mosaic variant is the least common pattern of transmission of DS, occurring in $1 \%-2 \%$ of people with DS, and the error in cell division occurs after fertilisation. ${ }^{6,25}$ Affected individuals have some cells with an extra chromosome 21 and others with the normal number, and this results in some body cells containing 47 chromosomes and others having the usual 46 chromosomes. ${ }^{6,25}$ The greater the number of normal cells in DS, the higher the chances of higher cognitive functions, with a possibility of less intellectual impairment. ${ }^{4}$ Like trisomy 21 , the mosaic type of DS is not inherited, ${ }^{5,14}$ and it is estimated that $1 \%-2 \%$ of people with DS are mosaic. . $^{25}$

\section{Neurobiology of Down syndrome}

The neurobiological sequelae of DS includes a variety of anatomic, physiological and biochemical alterations in the brains of patients of various ages. ${ }^{29,30,31,32,33,34,35}$ Investigations of neurobiological changes in DS started with autopsy studies, which were subsequently confirmed and expanded on using neuro-imaging techniques. The studies reveal that alterations in neural mechanisms at a chemical level (resulting from changes due to replication of chromosome 21 at the cellular level) affect the brain development processes. . $^{2,30,31,32,33,34,35}$ These change the neuropsychological profiles of individuals with DS including learning, language and behaviour. ${ }^{15,29,30}$

It is consistent in the literature that at birth, there are no neurological variations between individuals with DS and in the general population, $29,30,31,32,33,34,35$ although differences can be seen as early as 6 months..$^{29,30,31,32,33,34,35}$ The morphological characteristics unique to the brain in DS include being typically smaller with up to $20 \%$ reduction in volume ${ }^{29,30,31,32,33,34,35}$ disproportionately shorter skulls (brachycephaly), and decreased sizes of the frontal, occipital and temporal lobes, brainstem and cerebellum, as well as a smaller corpus callosum. Furthermore, the hippocampus and temporal lobes in children with DS are smaller in size.

These morphological changes affect body physiology and functions. A smaller cerebellum contributes to problems of hypotonia (poor muscle tone), motor coordination, articulation, as well as language and general intelligence in DS. The reduced size of the hippocampus could account for specific memory and language deficits in DS. ${ }^{29,30,31,32,33,34,35}$ 
The smaller superior gyrus (STG) in DS contributes to language deficits as STG contains the primary auditory cortex (region responsible for sound) as well as Wernicke's area (region responsible for speech and language recognition). ${ }^{29,30,31,32,33,34,35}$ Neuro-imaging studies ${ }^{29,30,31,32,33,34,35}$ also provided data on brain characteristics of persons with DS at the cellular level. These features include fewer granule cells in the cerebellum, defects in cortical lamination, reductions in the amount of cortical neurons, presence of malformations in dendritic spines, as well as synaptic abnormalities. ${ }^{29,30,31,32,33,34,35}$ Dendrites are the main receptive structures of neurons, and dendritic spines host the majority of neuronal synapses. In the DS brain, the numbers of dendrites are reduced and there are less synapses that are often clustered irregularly. $29,30,31,32,33,34,35$ An infant with DS has a rapidly growing dendritic tree, which connects neurons together. ${ }^{29,30,31,32,33,34,35}$ These dendrites grow within 1 year of birth and the growth slows subsequently. Abnormal development of the dendritic structures is a hallmark sign of ID in DS. $29,30,31,32,33,34,35$

\section{Epidemiology of Down syndrome}

The epidemiology of DS including the risk factors, incidence and prevalence estimates has been documented extensively., ${ }^{8,26,27}$ The risk factors for trisomy 21 include AMA, altered or aberrant recombination, occurrence of a previous trisomy birth and environmental factors. Advancing maternal age and aberrant recombination remain the only conclusive and well-documented risk factors for DS pregnancy. ${ }^{8,26,27}$ The risk of having a child with DS increases with AMA, which has been linked to biological ageing of the ovaries. ${ }^{22,25}$ About $85 \%-88 \%$ of DS is associated with errors from the maternal egg, about $5 \%-9 \%$ originates from the paternal sperm while the remaining $1 \%-3 \%$ are attributed to mitotic cell division errors that happen after fertilisation. ${ }^{8,24,26}$ The AMA risk factor in DS applies mainly to the trisomy 21 variant of DS. ${ }^{22,25}$ Although AMA is the primary risk factor for DS birth, due to higher birth rates in younger women, about $80 \%$ of children with DS are born to women under 35 years of age. ${ }^{14}$ The chances of having DS increases with age of mother at conception $^{6,7,14}$ (Figure 1).

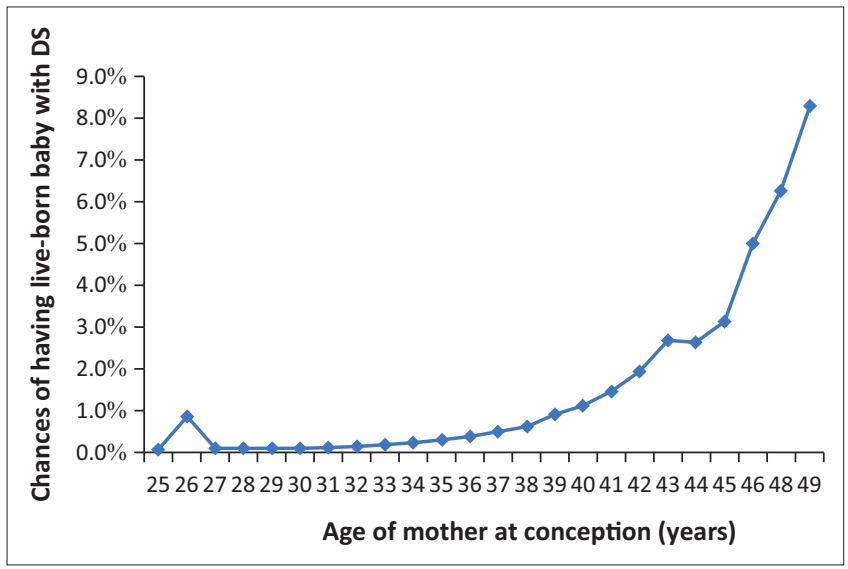

FIGURE 1: Chances of having a live-born baby with Down syndrome in relation to age of mother at conception (years).
The physiological mechanism that relates AMA to trisomy 21 births is not clear although several hypotheses have been developed to explain the process. Firstly, it has been speculated that the increased incidence of trisomic births with maternal age may be due to decreased rejection of abnormal embryos and increased errors in cell division with increasing maternal age. ${ }^{14,25}$ A common assumption in the maternal age-trisomy 21 relationship hypothesis is that an 'aged' ovum is less likely to fertilise and may be more prone to the errors that result in trisomy $21.8,14,25$ Furthermore, maternal hormonal imbalance causes a reduced microvasculature with a subsequent reduction in oxygen and a decrease in the intracellular $\mathrm{pH}$ of the oocytes (egg cells) that may suppress the maturation of the oocytes during the follicular phase and result in chromosomal displacement and non-disjunction.., 25

Recurrence risk as a factor expresses the possibility of women who had prior DS births to have subsequent ones. For women who had prior trisomy 21 child birth, there is an approximately $1 \%$ recurrence risk of having another child with trisomy 21. The carriers of a balanced translocation of chromosome 21 are also documented risk factors for DS pregnancy. ${ }^{5,25}$ The risk of having a child with DS is higher if the variant is translocation, which is the inherited type..$^{5,25}$

Another risk factor in DS conception is altered 'recombination patterns'. Although trisomy 21 is due mainly to errors in the final stage (chromosome segregation) of meiosis, considerable evidence has shown that errors in the second stage (recombination stage) prepare the cell for non-disjunction. ${ }^{25,26}$ Thus, reduced recombination invariably results in increased frequency of non-disjunction. ${ }^{25,26}$ Evidence from both cytogenetic and epidemiological studies suggests that various environmental and occupational exposures are also risk factors that may increase the chances of trisomy 21 birth. ${ }^{25,26}$ These factors include alcohol and nicotine, medications (oral contraceptives and spermicides, hormonal therapy, radiation therapy and fertility medications), toxic wastes and infections. ${ }^{25,26}$

The incidence (new cases) and prevalence (existing cases) of DS vary across regions. DS is the most common chromosomal abnormality in humans occurring in approximately between 1 in 600-1000 live births worldwide. ${ }^{25,29}$ In the United States of America, for instance, an estimated 5500 infants with DS are born annually. ${ }^{10}$ The incidence of births of children with DS increases with the age of the mother. The factors that may influence the birth incidence of $\mathrm{DS}^{25,28}$ include the following:

- Changes in the maternal age distribution in the population.

- The availability and use of prenatal testing.

- Socio-cultural factors. For example, in a country such as the United Arab Emirates where termination of pregnancy is illegal, the incidence would be higher than in France and the Netherlands where termination of pregnancy is legal. These variations may be related to a high percentage of DS pregnancy terminations. ${ }^{28}$ 
The prevalence of DS is influenced by improved survival rates for infants with DS, which is related to improved medical care (especially of cardiovascular malformations).$^{28}$ Although the incidence of DS seems stable, the prevalence (existing cases) is increasing. With advanced medical care, more children survive to adulthood with a subsequent increased longevity. ${ }^{28}$ More so, with increased public education, awareness and increased interaction between individuals with DS and the general population, the population of people with DS is likely to increase..$^{5,28}$ These factors may outweigh the effects of prenatal diagnosis and termination of pregnancy. ${ }^{28}$ The incidence of DS per live births varies across countries and the estimates for some countries are outlined in Table 1. . $^{36,37,38,39,40,41,42}$

\section{Characteristic physical and health implications of Down syndrome}

DS is a multisystem disorder that affects the individual physically, medically and psychologically. The physical -

\begin{tabular}{llc}
\multicolumn{3}{l}{ TABLE 1: Prevalence of live births of Down syndrome across regions. } \\
\hline Area & Prevalence & Percentage \\
\hline Australia & $1: 1150$ live births & 0.08 \\
Israel & 1 in 1000 & 0.1 \\
Nigeria & 1 in 865 & 0.11 \\
UK & I in 1000 & 0.11 \\
Norway & 1.25 in 1000 live births & 0.12 \\
USA & 1 in 691 babies & 0.14 \\
The Netherlands & 16 in 10 000 & 0.16 \\
Saudi Arabia & 1 in 554 & 0.18 \\
Sweden & 1 in 800 & 0.12 \\
South Africa & $1.33-1.8$ per 1000 (coloured and whites) & $0.13-0.18$ \\
& 2.1 per 1000 (mainly black population) & 0.21 \\
Canada & $1 / 449$ & 0.22 \\
Dubai & 2.32 in 1000 & 2.23 \\
\hline
\end{tabular}

Source: Australia ${ }^{15}$, Israel ${ }^{36}$, Nigeria $^{37}$, UK $^{38}$, Norway $^{38}$, USA $^{14}$, The Netherlands ${ }^{39}$, Saudi Arabia $^{40}$, Sweden ${ }^{41}$, South Africa ${ }^{42}$, Canada ${ }^{12}$, Dubai ${ }^{36}$

Note: Please see the full reference list of the article, Wajuihian SO. Down syndrome: An overview. Afr Vision Eye Health. 2016;75(1), a346. http://dx.doi.org/10.4102/aveh. v75i1.346, for more information. head, face and neck - features ${ }^{2,5,15}$ include brachycephaly (disproportionately shorter or small head or skull shape), unusually round face, short neck, low-set, small ears, flat nasal bridge, microgenia (an abnormally small chin), macroglossia (protruding or oversized tongue) due to small oral cavity, small chin, almond shape to the eyes caused by an epicanthic fold of the eyelid and oblique palpebral fissures. Other features include shorter limbs, a single transverse palmar crease (a single instead of a double crease across one or both palms), lax ligaments, excessive space between large toe and second toe, dry skin, muscle hypotonia (poor muscle tone) and brachydactyly (shorter fingers and toes). Ocular and visual features of DS include high refractive errors, amblyopia and strabismus, accommodative and vergence anomalies, ptosis, blepharitis, nasolacrimal duct obstruction, nystagmus, keratoconus, speckling of the iris (Brushfield's spots), cataracts, glaucoma and retinovascular anomalies. DS has considerable health implications and people with DS have an increased risk for certain medical conditions. The levels of abilities and disabilities vary due to variations in the level of affliction. Some medical conditions are congenital while others are progressive. ${ }^{43}$ DS cannot be treated, though many of the associated health conditions are treatable and people with DS now live healthier lives. ${ }^{15}$ The major health conditions associated with DS. ${ }^{5,711,15}$ are summarised in Table 2.

\section{Screening and diagnosing Down syndrome}

Given the health consequences of DS births, some parents may opt to undergo some prenatal tests to screen for the risks of the foetus having DS. There are two types of tests for DS, namely, screening and diagnostic tests. The prenatal screenings do not give definite results but provide the probability of a foetus having DS. If a screening test gives a positive finding for DS, a pregnancy may have DS, a diagnostic test is performed to confirm if the baby actually

TABLE 2: Health implications of Down syndrome.

\begin{tabular}{|c|c|}
\hline Systems & Conditions \\
\hline Cardiac defects & $\begin{array}{l}\text { Incidence of congenital heart disease in DS is between } 44 \% \text { and } 50 \% \text {. Commonly atrial septal (wall of the heart) defects and } \\
\text { ventricular septa defects }\end{array}$ \\
\hline Cognitive & $\begin{array}{l}\text { Mainly intellectual disability which affects learning, memory, and language that leads to mild-to profound impairment in } \\
\text { intellectual functioning }\end{array}$ \\
\hline Gastrointestinal & Commonly feeding difficulties and gastro-oesophageal reflux \\
\hline Dermatological & Dry skin, folliculitis, vitiligo \\
\hline Neurology & Developmental deficiencies; mainly intellectual disability \\
\hline Respiratory & Due to an enlarged tongue, uvula and soft palate predisposes towards obstruction \\
\hline Central nervous system & Dementia and Alzheimer's disease in adults \\
\hline Ear nose and throat & Conductive and sensori-neural hearing loss, sleep-related breathing disorders (such as sleep apnea) and chronic catarrh \\
\hline Orthopaedic & Cervical spine disorders, joint and muscle problems \\
\hline Reproduction & $\begin{array}{l}\text { Impaired fertility both genders; males are usually unable to father children, while females have fertility and birth problems } \\
\text { including miscarriages, premature births and difficult labour }\end{array}$ \\
\hline Dental & Include caries and malocclusion \\
\hline Endocrine/growth anomalies & Commonly hypothyroidism, hyperthyroidism, obesity and diabetes, impaired stimulation of growth hormone. \\
\hline Haematological/oncology & Mainly leukaemia \\
\hline Immunological & $\begin{array}{l}\text { Immune dysfunction, autoimmune disease such as arthropathy, vitiligo, alopecia } \\
\text { Increased susceptibility to infections than normal children }\end{array}$ \\
\hline Neuropsychiatric/behavioural & $\begin{array}{l}\text { Common neuropsychiatric problems in DS children include epilepsies, autistic spectrum disorder, depressive illness, dementia } \\
\text { (adults), attention deficit hyperactivity disorder, conduct/oppositional disorder }(5.4 \%) \text {, or aggressive behaviour. }\end{array}$ \\
\hline
\end{tabular}

DS, Down syndrome. 
has DS., ${ }^{5,14}$ Therefore a diagnostic, unlike the screening test, provides a definite diagnosis with almost $100 \%$ accuracy. 5,14

\section{Conclusion}

DS is a genetic anomaly with considerable oculo-visual and medical consequences. Optometry's role is crucial in alleviating the impact of vision anomalies in individuals with DS. This role can be better achieved if optometrists acquire the basic understanding of the disorder. Future review papers will focus on the oculo-visual anomalies and detail the role of optometry in addressing vision anomalies in DS.

\section{Acknowledgements}

I am grateful to Mr K.P. Mashige and Dr Samuel Bert BoadiKusi for reviewing the semi-final drafts of the manuscript.

\section{Competing interests}

The author declares that he has no financial or personal relationships which may have inappropriately influenced him in writing this article.

\section{References}

1. Sands W, Taub M, Maino D. Limited research and education on special populations in optometry and ophthalmology. Optom Vis Dev. 2008;39:60-61.

2. Maino D. Overview of special populations. In: Scheiman $M$, Rouse $M$, editors. Optometric management of learning-related vision problems, 1st ed. St. Louis, MO: Mosby, 2006; p. 85-106.

3. Adio AO, Wajuihian SO. Ophthalmic manifestations of children with Down syndrome in Port Harcourt, Nigeria. Clin Ophthalmol. 2012;6:1859-1864. http:// dx.doi.org/10.2147/OPTH.S36685

4. Duckman RH. Visual status of children with Down syndrome. Optom Vis Perf. 2014;2:240-243.

5. Baum RA, Nash PL, Jessica EA, Foster JE, Spader M. Primary care of children and adolescents with Down syndrome: An update. Curr Probl Pediatr Adolesc Health Care. 2008;38:241-261. http://dx.doi.org/10.1016/j.cppeds.2008.07.001

6. Barlow-Stewart K. Trisomy 21 - Down syndrome. Fact sheets 6,7 and 28 and Centre for Genetics Education. [cited 2015 Oct 5]. Available from http://www. genetics.edu.au

7. Ahmad M, Silvera-Redondo C, Rodríguez $\mathrm{MH}$. Nondisjunction and chromosomal anomalies. Salud Uninorte Barranquilla. 2010;26:117-133.

8. Ghosh S, Subrata KD. Risk factors for Down syndrome birth: Understanding the causes from genetics and epidemiology. [cited 2015 Dec 12]. Available from http://cdn.intechopen.com/pdfs-wm/43386.pdf

9. Petersen MB, Mikkelsen M. Non-disjunction in trisomy 21: Origin and mechanisms. Cytogenet Cell Genet. 2000;91:199-203. http://dx.doi.org/10.1159/000056844

10. Bittles AH, Bower C, Hussain R, Glasson EJ. The four ages of Down syndrome. Eur J Public Health. 2007;17:221-225. http://dx.doi.org/10.1093/eurpub/ ckl103

11. Leshin L. Pediatric health update on Down syndrome. In: Cohen WI, Nadel L, Madnick ME editors. Down syndrome visions for the 21st century. New York: Wiley-Liss, Inc., 2002; p. 187-201.

12. Canadian Down syndrome society. [cited 2015 Dec 12]. Available from http:// www.cdss.ca/information/general-information/what-is-down-syndrome.html

13. Megarbane A, Ravel A, Mircher C, et al. The 50th anniversary of the discovery of trisomy 21: The past, present, and future of research and treatment of Down syndrome. Gene Med. 2009;11:611-616. http://dx.doi.org/10.1097/GIM. 0b013e3181b2e34c

14. Down syndrome. [cited 2015 July 13]. Available from http://www.ndss.org/DownSyndrome/What-Is-Down-Syndrome
15. Tracy J. Australians with Down syndrome-Health matters. Aust Fam Physician. 2011;40:202-208.

16. Shuttleworth GE. Clinical lecture on idiocy and imbecility. $\mathrm{Br}$ Med J. 1886;1:183-186. http://dx.doi.org/10.1136/bmj.1.1309.183

17. Shuttleworth GE. Mongolian imbecility. Br Med J. 1909;2:661-665.

18. Down JL. Observations on ethnic classification of idiots. London Hosp Rep. 1866;111(1-3):259-262.

19. Goplerud JM. Down syndrome, historical perspective, past, present and present. Pediatr Res. 1999;45:124. http://dx.doi.org/10.1203/00006450-199904020-00738

20. Cullen JF, Butler HG. Mongolism (Down's syndrome) and keratoconus. $\mathrm{Br} J$ Ophthalmol. 1963;47:321-330. http://dx.doi.org/10.1136/bjo.47.6.321

21. Jacobs PA, Baikie AG, Court Brown WM. The somatic chromosomes in mongolism. Lancet. 1959;1:710. http://dx.doi.org/10.1016/S0140-6736(59)91892-6

22. Girirajan S. Parental-age effects in Down syndrome. J Genet. 2009;88:1-7. http:// dx.doi.org/10.1007/s12041-009-0001-6

23. Francisco C. History of Down syndrome. A full count of players. Can Pediatr. 2010;34:157-159.

24. Noble J. Natural history of Down's syndrome: A brief review for those involved in antenatal screening. J Med Screen. 1998;5:172-177. http://dx.doi.org/10.1136/ jms.5.4.172

25. Sherman SL, Allen EG, Bean LH. Epidemiology of Down syndrome. Ment Retard Dev Disabil Res Rev. 2007;13:221-227. http://dx.doi.org/10.1002/mrdd.20157

26. Hassold T, Sherman S. The origin and etiology of trisomy 21. In: Cohen WI, Nade L, Madnick ME, editors. Down syndrome: Visions for the 21st century. New York Wiley-Liss, 2002; p. 295-301.

27. Hassold $T$, Hall $H$, Hunt $P$. The origin of human aneuploidy: Where we have been where we are going. Hum Mol Genet. 2007;16:203-208. http://dx.doi org $/ 10.1093 / \mathrm{hmg} / \mathrm{ddm} 243$

28. Weijerman ME, Winter P. The care of children with Down syndrome. Eur J Pediatr 2010;169:1445-1452. http://dx.doi.org/10.1007/s00431-010-1253-0

29. Fernández-Alcaraz C, Carvajal-Molina F. Cytogenetic and neurobiological advances in down syndrome. Anales de Psicología. 2014;1:346-354.

30. Dierssen M, Herault $Y$, Estiv X. Aneuploidy: From a physiological mechanism of variance to Down syndrome. Physiol Rev. 2009;89:887-920. http://dx.doi. org/10.1152/physrev.00032.2007

31. Contestabile A, Benfenati F, Gasparini L. Communication breaks-Down: From neurodevelopment defects to cognitive disabilities in Down syndrome. Pro Neurobiol. 2010;91:1-22. http://dx.doi.org/10.1016/j.pneurobio.2010.01.003

32. Fidler DJ, Nadel L. Education and children with Down syndrome: Neuroscience, development, and intervention. Ment Retard Dev Disabil Res Rev. 2007;13:262271. http://dx.doi.org/10.1002/mrdd.20166

33. Pennington BF, Moon J, Edgin J, Stedron J, Nadel L. The neuropsychology of Down syndrome: Evidence for hippocampal dysfunction. Child Dev. 2003;74:75-93. $\mathrm{http}: / / \mathrm{dx}$.doi.org/10.1111/1467-8624.00522

34. Nadel L. Down's syndrome: A genetic disorder in behavioral perspective. Genes Brain Behav 2003;2:156-166. http://dx.doi.org/10.1034/j.1601-183X.2003.00026.x

35. Nowinski W. Introduction to brain anatomy. [cited 2015 Nov 19]. Available from http:// www.springer.com/.../9781441999962

36. Murthy SK, Ashok KM, Mani S, Shara MEA, Al-Rowaished EEM. Incidence of Down syndrome in Dubai, UAE. Med Princ Pract. 2007;16:25-28. http://dx.doi. org/10.1159/000096136

37. Adeyokunnu AA. The incidence of Down's syndrome in Nigeria. J Med Genetics 1982;19:277-279. http://dx.doi.org/10.1136/jmg.19.4.277

38. Haugen $\mathrm{OH}$, Hodvig G. Strabismus and binocular function in children with Down syndrome: A population-based, longitudinal study. Acta Ophthalmol Scand. 2001;79:133-139. http://dx.doi.org/10.1034/j.1600-0420.2001.079002133.x

39. Weijerman ME, van Furth AM, Vonk Noordegraaf A. Prevalence, neonatalcharacteristics and first-year mortality of Down syndrome: A national neonatalcharacteristics and first-year mortality of Down syndrome: A national
study. J Pediatrics. 2008:152:15-19. http://dx.doi.org/10.1016/j.jpeds.2007. study.

40. Al-Shawaf R, Al-Faleh W. Craniofacial characteristics in Saudi Down's syndrome. King Saud University J Dent Science. 2011;2:17-22. http://dx.doi.org/10.1016/j. ksujds.2010.12.001

41. Myrelid A, Gustafsson MA, Ollars B, Annerén G. Growth charts for Down's syndrome from birth to 18 years of age. Arch Dis Child 2002;87:97-103. http:// dx.doi.org/10.1136/adc.87.2.97

42. Urban MF, Stewart C, Ruppelt T, Geerts L. Effectiveness of prenatal screening for Down syndrome on the basis of maternal age in Cape Town. S Afr Med J. 2011;101:45-48. http://dx.doi.org/10.7196/SAMJ.4188

43. Haydar TF, Reeves RH. Trisomy 21 and early brain development. Trends Neurosci. 2012;35:81-91. http://dx.doi.org/10.1016/j.tins.2011.11.001 